\title{
Um curso de Mecânica com o uso do programa de videoanálise Tracker ${ }^{+*}$
}

Júlia Esteves Parreira ${ }^{1}$

Departamento de Física e Química

PUC-Minas

Belo Horizonte - MG

\section{Resumo}

Neste texto serão apresentados diversos experimentos que podem ser feitos com o auxílio do programa de computador Tracker para o estudo da Mecânica. Todos os assuntos tratados em disciplinas de Mecânica do Ensino Médio e do ciclo básico do Ensino Superior são contemplados por essas práticas. Tais disciplinas podem ser ministradas abordandose, quase exclusivamente, problemas reais observados pelos alunos em sala de aula, tendo seus parâmetros medidos através do programa.

Palavras-chave: Tracker; Videoanálise; Ensino de Física.

\begin{abstract}
In this text will be presented several experiments that can be done with the aid of the computer program Tracker for the study of mechanics. All subjects of Mechanics presented in the disciplines of High School and the firt year of undergraduate courses are covered by these practices. These courses can be taught by addressing, almost exclusively, real problems, observed by the students in the classroom, having their parameters measured through the program.
\end{abstract}

Keywords: Tracker; Video Analysis; Physics Education.

\footnotetext{
${ }^{+}$A mechanics course with the use of the Tracker video analysis

* Recebido: outubro de 2017. Aceito: novembro de 2018.

${ }^{1}$ E-mail: julia@pucminas.br
} 


\section{Introdução}

O Tracker é um programa de computador para videoanálise, gratuito e livre. Através dele filma-se um movimento que se queira analisar e se obtém, a partir da localização do objeto em cada quadro do vídeo, medidas de posição e tempo. É possível obtê-lo (BROWN, 2017) e instalá-lo de forma fácil e rápida. Instruções de instalação e utilização podem ser facilmente encontradas na internet (BROWN, 2017). Esse programa vem sendo cada vez mais utilizado no ensino de Física. Há muitas publicações recentes, artigos em revistas, trabalhos apresentados em congressos de Ensino de Física e até mesmo livro, dedicados a esse tema (JESUS, 2014; CHRISTIAN, 2011; RODRIGUES, 2013; SIRISATHITKUL, 2013; WRASSE, 2014; BEZERRA, 2012).

A principal contribuição deste trabalho consiste em demonstrar como é possível planejar toda uma disciplina de Mecânica abordando-se, quase exclusivamente, situações observadas, registradas e analisadas em sala de aula, em contraponto a situações hipotéticas, retiradas de livros didáticos. Isso é válido tanto para o Ensino Médio quanto para disciplinas do primeiro ano de cursos superiores da área de Ciências Exatas.

Será apresentada ao longo do texto uma sequência de situações que podem ser trabalhadas em sala de aula, contemplando todos os tópicos estudados em Mecânica. Todas as práticas descritas e citadas necessitam de poucos materiais de baixo custo. Elas vêm sendo utilizadas pela autora deste artigo em disciplinas de Física 1 de diversos cursos de Engenharia, na universidade particular em que leciona. Observa-se que, ao longo do semestre, os estudantes vão adquirindo mais habilidade no uso do Tracker e vão cada vez mais considerando a possibilidade de observar a Física nos eventos do dia-a-dia e de utilizar o Tracker para tal fim. Em um dos semestres letivos em que a disciplina foi ministrada dessa maneira, todos os grupos de uma turma com cerca de 40 alunos utilizaram o Tracker em seus trabalhos interdisciplinares.

A aceleração é uma grandeza de central importância em qualquer disciplina de Mecânica. No entanto, é raro que uma única medida de aceleração seja feita durante um curso. Normalmente, espera-se que os estudantes aceitem, sem instrumentos para verificar a veracidade, que movimentos com aceleração constante estão muito presentes em nosso cotidiano, como um objeto que cai em queda livre ou um bloco que escorrega em uma rampa, com ou sem atrito. Além disso, costuma-se considerar, sem nenhuma justificativa palpável, que a resistência do ar tem efeito desprezível em um número enorme de movimentos analisados durante a disciplina.

A utilização de um smartphone e de um computador com o software Tracker nos possibilitam tornar o conceito de aceleração mais acessível, facilitando, consequentemente, a compreensão da $2^{\text {a }}$ lei de Newton. Pode-se responder empiricamente, na sala de aula, a diversas questões que são levantadas pelos estudantes, tais como: a resistência do ar é realmente desprezível no movimento de uma caneta que cai da mesa ao chão? O atrito cinético é uma força constante? As componentes horizontal e vertical do movimento de um projétil têm re- 
almente velocidade e aceleração constantes, respectivamente? A $2^{\mathrm{a}}$ lei de Newton realmente é útil para prever características do movimento de objetos, como o da máquina de Atwood?

Utilizando-se o Tracker para a análise do movimento, trabalha-se, em cada situaçãoproblema, com aquisição de dados experimentais, análise de gráficos e análise da equação de movimento obtida a partir do ajuste de uma função aos dados experimentais para obtenção de informações que dizem respeito ao movimento. Essa forma de abordagem possibilita que os estudantes analisem as diferentes representações do movimento e suas interrelações. Com a vantagem de ser feita essa análise a partir de uma situação real, observada por eles.

O tempo gasto para se fazer a filmagem, obter os dados, produzir os gráficos e encontrar as equações de movimento não passa de cinco minutos para uma pessoa que conheça bem o programa.

A adoção dessa prática em sala de aula é simples e requer a utilização de muito pouco material. Com um computador e um smartphone já é possível se fazerem muitos experimentos interessantes. Acrescentando-se outros materiais, como uma polia, uma balança, um brinquedo Flat Ball e um dinamômetro, amplia-se ainda mais o espectro de situações exploráveis, enriquecendo o curso.

Os roteiros das práticas utilizados pela autora deste artigo com seus alunos estão disponíveis em seu blog institucional (PARREIRA, 2018). As aulas em que o Tracker foi utilizado ocorreram em uma sala de informática da Universidade, de forma que os próprios estudantes puderam filmar o evento a ser analisado, com seus telefones, e, individualmente ou em pequenos grupos, fizeram a análise no computador. Também é possível organizar a aula de forma a se fazer uma única filmagem e utilizar apenas um computador e um projetor e trabalhar coletivamente, com toda a turma. Estes experimentos ainda podem ser utilizados em aulas de Física Experimental.

Ressalta-se que o uso da ferramenta aqui descrita visa unicamente a substituição da análise de situações hipotéticas pela análise de situações reais, que podem ser observadas pelos estudantes durante a aula. De forma que toda a fundamentação teórica pode ser empregada em tais análises, mas não substituída por elas.

Na seção II deste artigo, será apresentada uma análise básica dos movimentos de velocidade constante e de aceleração constante. Na seção III, serão descritos experimentos simples, típicos de livros didáticos, que podem ser feitos em sala de aula e analisados com o auxílio do Tracker em disciplinas de Mecânica, todos estão listados na Tabela 1. Na tabela estão enumerados os materiais necessários para cada prática e expostas as referências bibliográficas que descrevem a utilização do Tracker para estudar os mesmos tipos de fenômenos, não necessariamente da mesma forma. A seção IV traz a conclusão do trabalho.

Todas as figuras deste trabalho foram produzidas pela autora do mesmo. Algumas são fotografias e outras capturas de tela do programa Tracker, do computador. 
Tabela 1 - Experimentos analisados com utilização do Tracker, materiais e referências.

\begin{tabular}{|c|c|c|c|c|c|c|c|c|}
\hline $\begin{array}{l}\text { Materiais neces- } \\
\text { sários para cada } \\
\text { experimento }\end{array}$ & Polia & $\begin{array}{l}\text { Dina- } \\
\text { mô- } \\
\text { metro }\end{array}$ & $\begin{array}{l}\text { Balan- } \\
\text { ça }\end{array}$ & $\begin{array}{l}\text { Tábua } \\
\text { (ou } \\
\text { tampo } \\
\text { de } \\
\text { mesa) }\end{array}$ & Mola & $\begin{array}{l}\text { Flat } \\
\text { ball } \\
\text { ou } \\
\text { trilho } \\
\text { de ar }\end{array}$ & $\begin{array}{l}\text { Tele- } \\
\text { fone } \\
\text { celu- } \\
\text { lar, } \\
\text { com- } \\
\text { puta- } \\
\text { dor e } \\
\text { régua }\end{array}$ & Referencias \\
\hline $\begin{array}{l}\text { Movimento reti- } \\
\text { líneo uniforme }\end{array}$ & & & & & & $\mathrm{x}$ & $X$ & Jesus, 2014 \\
\hline $\begin{array}{l}\text { Plano inclinado } \\
\text { sem atrito }\end{array}$ & & & & & & $\mathrm{x}$ & $\mathrm{X}$ & \\
\hline Queda livre & & & $\begin{array}{l}\text { opcio- } \\
\text { nal }\end{array}$ & & & & $\mathrm{X}$ & $\begin{array}{l}\text { Jesus, 2014; } \\
\text { Rodrigues, } 2013\end{array}$ \\
\hline $\begin{array}{l}\text { Queda com re- } \\
\text { sistência }\end{array}$ & & & $\begin{array}{l}\text { opcio- } \\
\text { nal }\end{array}$ & & & & $\mathrm{X}$ & $\begin{array}{l}\text { Jesus, 2014; } \\
\text { Rodrigues, } 2013\end{array}$ \\
\hline $\begin{array}{l}\text { Movimento de } \\
\text { projétil }\end{array}$ & & & $\begin{array}{l}\text { opcio- } \\
\text { nal }\end{array}$ & & & & $\mathrm{X}$ & $\begin{array}{l}\text { Klein, 2014; } \\
\text { Lenz, 2014; Wee, } \\
2012\end{array}$ \\
\hline $\begin{array}{l}\text { Máquina } \quad \text { de } \\
\text { Atwood }\end{array}$ & $\mathrm{x}$ & $\begin{array}{l}\text { opcio- } \\
\text { nal }\end{array}$ & $\mathrm{x}$ & & & & $\mathrm{X}$ & \\
\hline $\begin{array}{l}\text { Movimento } \\
\text { harmônico sim- } \\
\text { ples - Conserva- } \\
\text { ção de energia } \\
\text { mecânica }\end{array}$ & & & $\mathrm{x}$ & & $\mathrm{x}$ & & $\mathrm{X}$ & Bryan, 2004 \\
\hline $\begin{array}{ll}\text { Coeficiente } & \text { de } \\
\text { atrito (1) } & \\
\end{array}$ & $\mathrm{x}$ & & $\mathrm{x}$ & $\mathrm{x}$ & & & $\mathrm{X}$ & \multirow[t]{2}{*}{ Jesus, 2014} \\
\hline $\begin{array}{l}\text { Coeficiente } \mathrm{de} \\
\text { atrito (2) }\end{array}$ & & & $\mathrm{x}$ & $\mathrm{x}$ & & & $\mathrm{X}$ & \\
\hline Colisões & & & $\mathrm{x}$ & & & $\mathrm{x}$ & $\mathrm{X}$ & \\
\hline $\begin{array}{l}\text { Medida do mo- } \\
\text { mento de inércia } \\
\text { - Objetos rolan- } \\
\text { do }\end{array}$ & & & $\mathrm{x}$ & $\mathrm{x}$ & & & $\mathrm{X}$ & $\begin{array}{l}\text { Jesus, 2014; Pro- } \\
\text { mmarach, } 2012\end{array}$ \\
\hline
\end{tabular}

\section{Uso do Tracker para encontrar velocidade e aceleração de movimentos com veloci- dade constante e com aceleração constante}

O uso do Tracker proporciona uma forma rica para a análise de movimentos retilíneos com velocidade ou aceleração constantes. O movimento deve ser filmado e o filme transferido para o computador. Este registro pode ser feito com os aparelhos celulares dos estudantes, uma máquina filmadora ou uma webcam. Durante a filmagem a câmera deve permanecer fixa e o plano do movimento deve ser perpendicular à direção determinada pela linha objetocâmera. É importante manter algo na cena (no mesmo plano do movimento do objeto) que sirva de referencial de tamanho, podendo ser o próprio objeto, uma régua ou uma pessoa, por exemplo. A qualidade dos dados depende sensivelmente de uma boa calibração através do 
referencial de tamanho. A principal fonte de erro nas medidas feitas através do Tracker reside na determinação de tal referencial. Como a concepção do curso não envolve cálculos de erros ou incertezas, esses não serão calculados no texto. O estudo de erros e incertezas já é feito, usualmente, em disciplinas de metrologia e física experimental, em cursos superiores de Ciências Exatas.

No computador, o filme deve ser aberto a partir do Tracker. No programa, assiste-se ao filme, quadro a quadro, e procede-se à marcação dos locais pelos quais o objeto de interesse passou. O resultado é o desenho de sua trajetória. O software fornece, então, as coordenadas de posição em função do tempo e, a partir desses dados, calcula a velocidade e a aceleração também em função do tempo. O programa pode ainda criar gráficos relacionando quaisquer pares de grandezas, bem como ajustar funções aos gráficos do experimento e definir novas grandezas, como energias e momentos.

No caso de um gráfico de posição em função do tempo, uma função de $1^{\circ}$ grau se ajustará adequadamente aos dados experimentais se o movimento tiver velocidade constante e uma função de $2^{\circ}$ grau se a aceleração for constante. Desse ajuste, podem-se obter os coeficientes das funções de $1^{\circ}$ ou de $2^{\circ}$ grau encontradas e determinar grandezas como velocidade e aceleração.

\section{II.1 Movimento retilíneo uniforme (MRU)}

A posição em função do tempo, $x(t)$, para um movimento uniforme pode ser representada pela função $x(t)=x_{0}+v$. $t$, em que $x_{0}$ representa a posição do objeto no tempo $t=0, v$ a velocidade e $t$ o tempo. Os coeficientes da função de $1^{\circ}$ grau ajustada ao gráfico experimental fornecerão os valores da posição do objeto no tempo $t=0$ e de sua velocidade.

A incerteza de cada um dos coeficientes é fornecida pelo programa em vários casos, sendo possível, a partir desse dado, verificar se o ajuste foi bem-sucedido e escolher o número adequado de algarismos significativos a serem considerados. Outro instrumento para avaliar se o ajuste feito foi pertinente é o valor do desvio quadrático médio ( $d q m)$ entre os dados experimentais e a função encontrada.

Tanto o valor da posição inicial quanto o sinal da velocidade dependerão da escolha do referencial durante a aquisição dos dados. No caso de o movimento ser unidimensional, deve-se orientar um dos eixos cartesianos em sua direção. Durante a aula, pode-se instruir os estudantes a mudarem a origem e a orientação dos eixos cartesianos do sistema de referência, a fim de se verificar qual é a alteração correspondente nos valores de posição inicial e de velocidade.

\section{II.2 Movimento retilíneo uniformemente variado (MRUV)}

Diversos movimentos com aceleração constante são estudados durante um curso de Mecânica. Como os estudantes podem se convencer de que realmente se tratam de movimentos com aceleração constante? Basta analisar cada um deles a partir do Tracker! 
A posição em função do tempo de um MRUV pode ser representada por uma função de $2^{\circ}$ grau. Com o software, obtêm-se os dados $x(t)$ do movimento sobre o qual se deseja investigar se tem ou não aceleração constante e, ao gráfico dos dados experimentais, faz-se o ajuste de uma função de $2^{\circ}$ grau. Se o ajuste for visualmente pertinente, já teremos um indício de que o movimento pode ser adequadamente modelado como tendo aceleração constante. Se, além disso, as incertezas dos coeficientes da função encontrada e o dqm do ajuste forem pequenos, teremos um argumento ainda mais forte sobre a natureza do movimento.

A análise de um movimento com aceleração constante é semelhante àquela do movimento com velocidade constante. No caso do MRUV, a posição em função do tempo pode ser expressa como $x(t)=x_{0}+v_{0} \cdot t+\frac{a \cdot t^{2}}{2}$, em que $v_{0}$ representa a velocidade no tempo $t=0$ e $a$ a aceleração do objeto.

\section{Exemplos de experimentos de Mecânica com o uso do Tracker}

\section{III.1 Movimento no plano horizontal sem atrito}

O MRU é frequentemente usado para introduzir o conceito de velocidade em Mecânica. No entanto, é uma situação difícil de ser produzida e observada em sala de aula. Uma opção muito boa, mas muito cara, é a utilização de um trilho de ar. Recentemente, foi lançado um brinquedo, o Flat Ball, que, ao soprar ar para baixo, se move flutuando. Sem atrito com o solo, seu movimento fica bem próximo de ser retilíneo e uniforme. O experimento para observação do MRU utilizando o Flat Ball tem a vantagem de ser muito mais barato do que aquele em que se utiliza um trilho de ar.

O movimento do Flat Ball sobre o chão pode ser filmado por cima e analisado pelo Tracker. Um bom resultado é encontrado, como pode ser visto nas Fig. 1 e 2. A Fig. 1 ilustra alguns pontos da trajetória separados por intervalos de tempo iguais e a Fig. 2 mostra o gráfico $x(t)$, com os pontos experimentais em verde e o ajuste linear em linha rosa. A função de $1^{\circ}$ grau ajustada pelo Tracker foi $x(t)=1,309 t+0,002$, estando as distâncias medidas em metros. Assim, conclui-se que a velocidade e a posição inicial do movimento foram: $v=$ $(1,309 \pm 0,003) \mathrm{m} / \mathrm{s}$ e $x_{0}=(0,002 \pm 0,002) \mathrm{m}$. As incertezas, que podem ser visualizadas na tela do computador passando-se o cursor sobre os valores dos coeficientes, não estão mostradas na figura.

\section{III.2 Plano inclinado sem atrito}

Um problema que é estudado em quase todo curso de Mecânica consiste em: dado um plano inclinado sem atrito, com determinada inclinação e comprimento, pede-se para que se calcule a aceleração, o tempo do percurso e a velocidade final. Um evento desse tipo pode ser observado com um Flat Ball que sobe e/ou desce qualquer superfície plana e inclinada. 
(2) Tracke:

Ficheiro Editar Vídeo Trajetórias Coordenadas Janela Ajuda

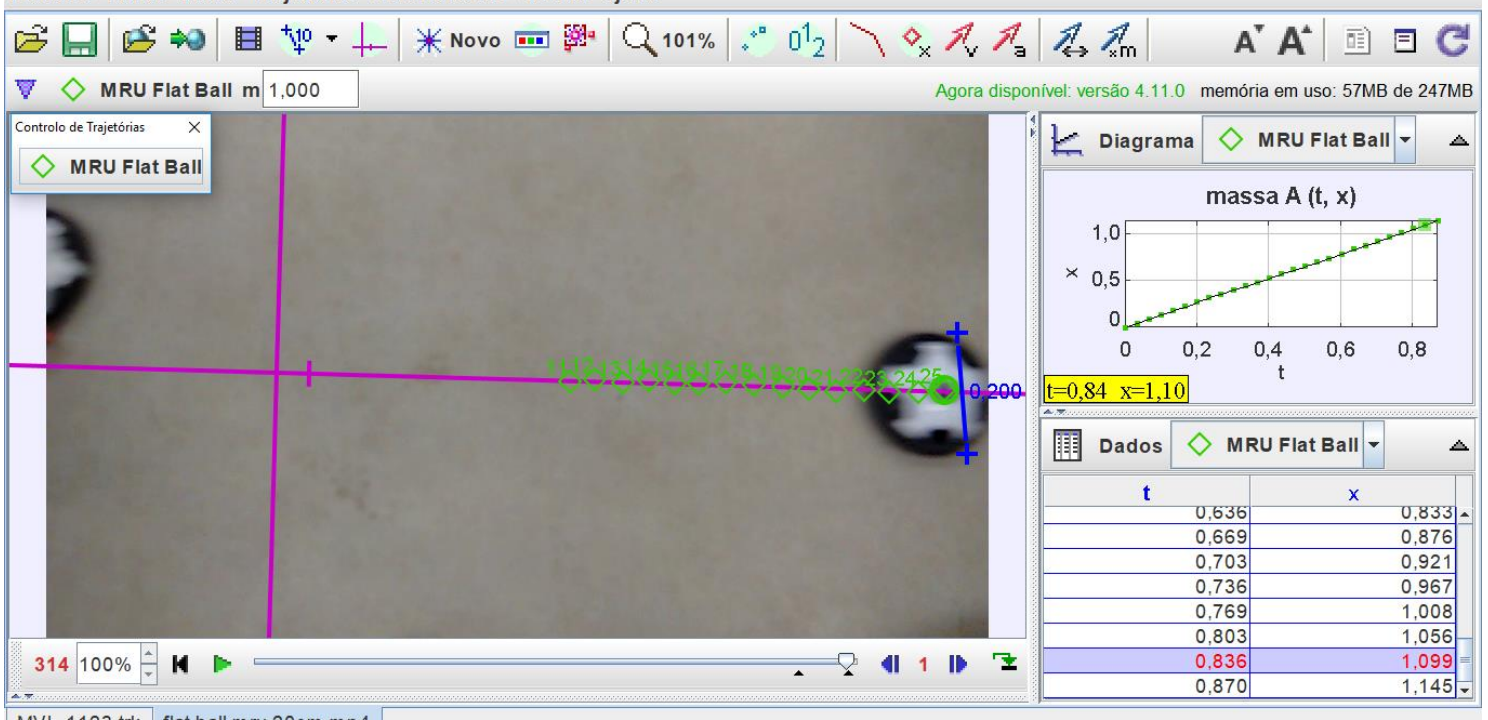

Fig. 1 - Pontos da trajetória do Flat Ball separados por intervalos de tempo constantes.

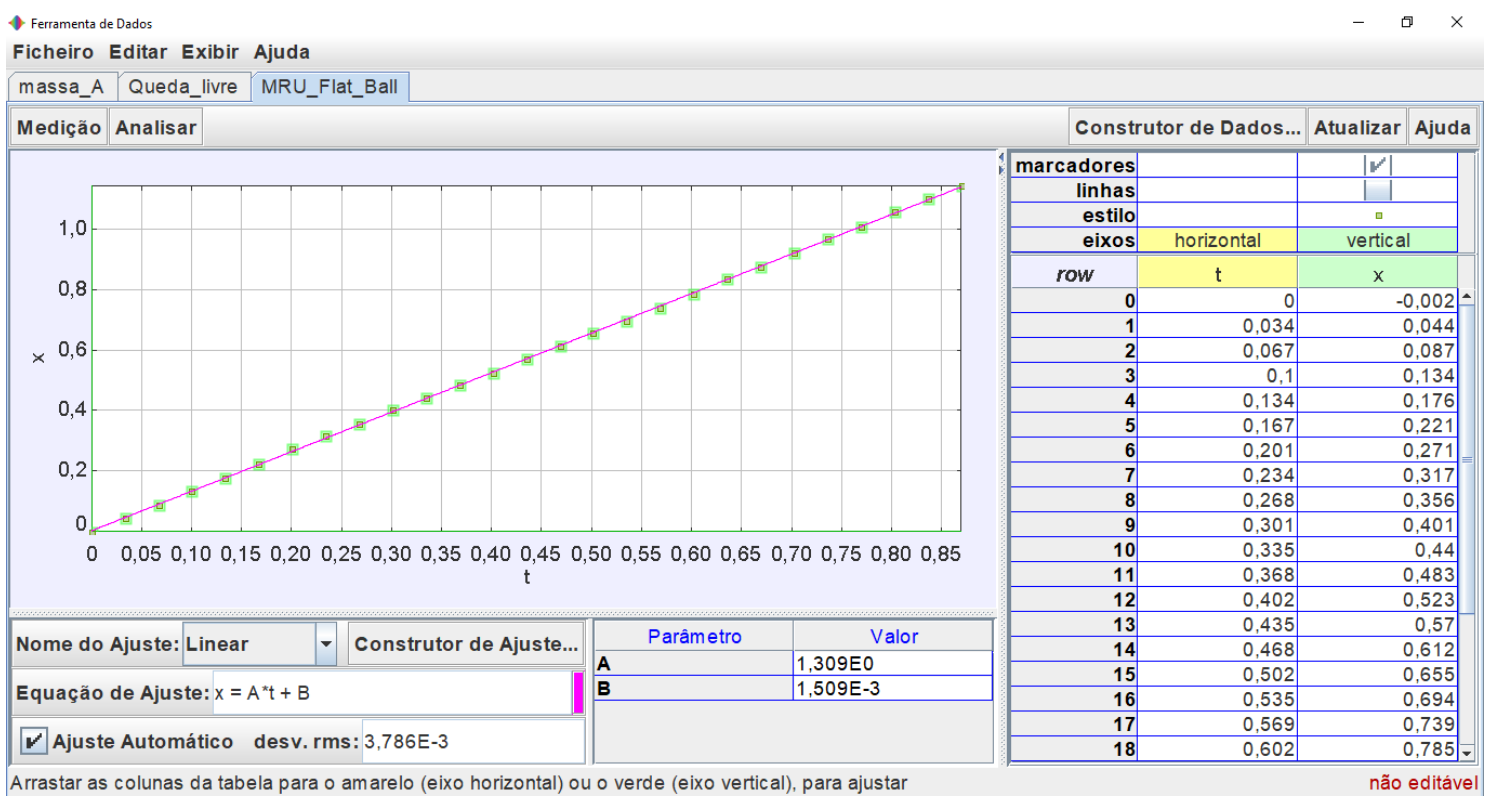

Fig. 2 - Gráfico x(t) do movimento do Flat Ball.

Todas as quantidades cinemáticas características desse movimento, posição, velocidade e aceleração em função do tempo, são facilmente medidas através do Tracker. Com isso, pode-se analisar na prática o movimento estudado em teoria, calculando e medindo as diversas grandezas a ele relacionadas, sendo possível confrontar os valores esperados teoricamente e os obtidos no experimento. 
Na Fig. 3 observa-se a tela de aquisição dos dados de posição em função do tempo para um Flat Ball deslizando sobre uma tábua inclinada a 3,1 ${ }^{\circ}$. A inclinação foi obtida medindo-se a altura da inclinação da rampa, $h$, com um paquímetro e o comprimento da rampa, $d$, com uma trena. O ângulo de inclinação é o arco-seno de $h / d$.

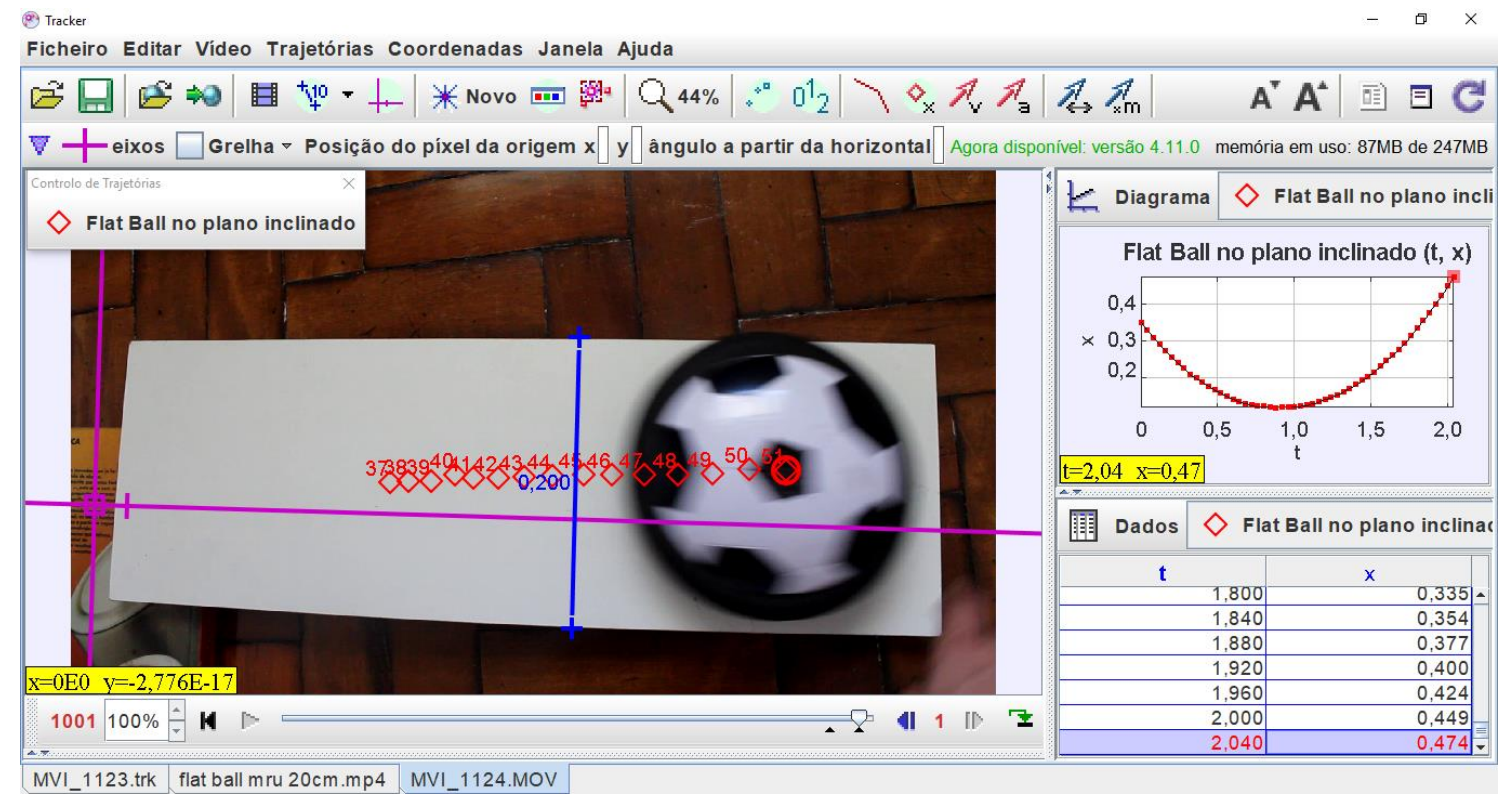

Fig. 3 - Tela do Tracker com aquisição de dados do movimento do Flat Ball sobre o plano inclinado a $3,1^{\circ}$.

A Fig. 4 traz o gráfico $x(t)$ com os pontos experimentais e o ajuste de função de $2^{\circ}$ grau. A função gerada foi: $x=0,28 t^{2}-0,51 t-0,35$. O dobro do coeficiente quadrático fornece a aceleração: $a=0,56 \mathrm{~m} / \mathrm{s}^{2}$. A análise do plano inclinado pela $2^{\mathrm{a}}$ Lei de Newton prevê que a aceleração seja igual $g$. $\sin \theta$, em que $g$ é a aceleração da gravidade e $\theta$ o ângulo que a trajetória faz com a horizontal. Para o caso em questão, essa previsão fornece o valor $a=0,53 \mathrm{~m} / \mathrm{s}^{2}$, em boa conformidade com a medida realizada através do Tracker.

\section{III.3 Objetos em queda}

\section{III.3.1 Queda livre - Medida da aceleração da gravidade}

Como saber se o movimento de queda livre tem realmente aceleração constante? Pode-se propor essa questão aos alunos e respondê-la junto a eles com a seguinte abordagem: se uma função de $2^{\circ}$ grau representa bem a posição em função do tempo para um objeto em queda livre, pode-se considerar que tal movimento apresenta aceleração constante. O bom ajuste pode ser verificado tanto visualmente, pela análise do gráfico do Tracker (no qual se pode observar simultaneamente os pontos referentes às medidas experimentais e à parábola repre- 
sentando a função de $2^{\circ}$ grau ajustada), quanto numericamente, através do $d q m$ fornecido pelo programa.

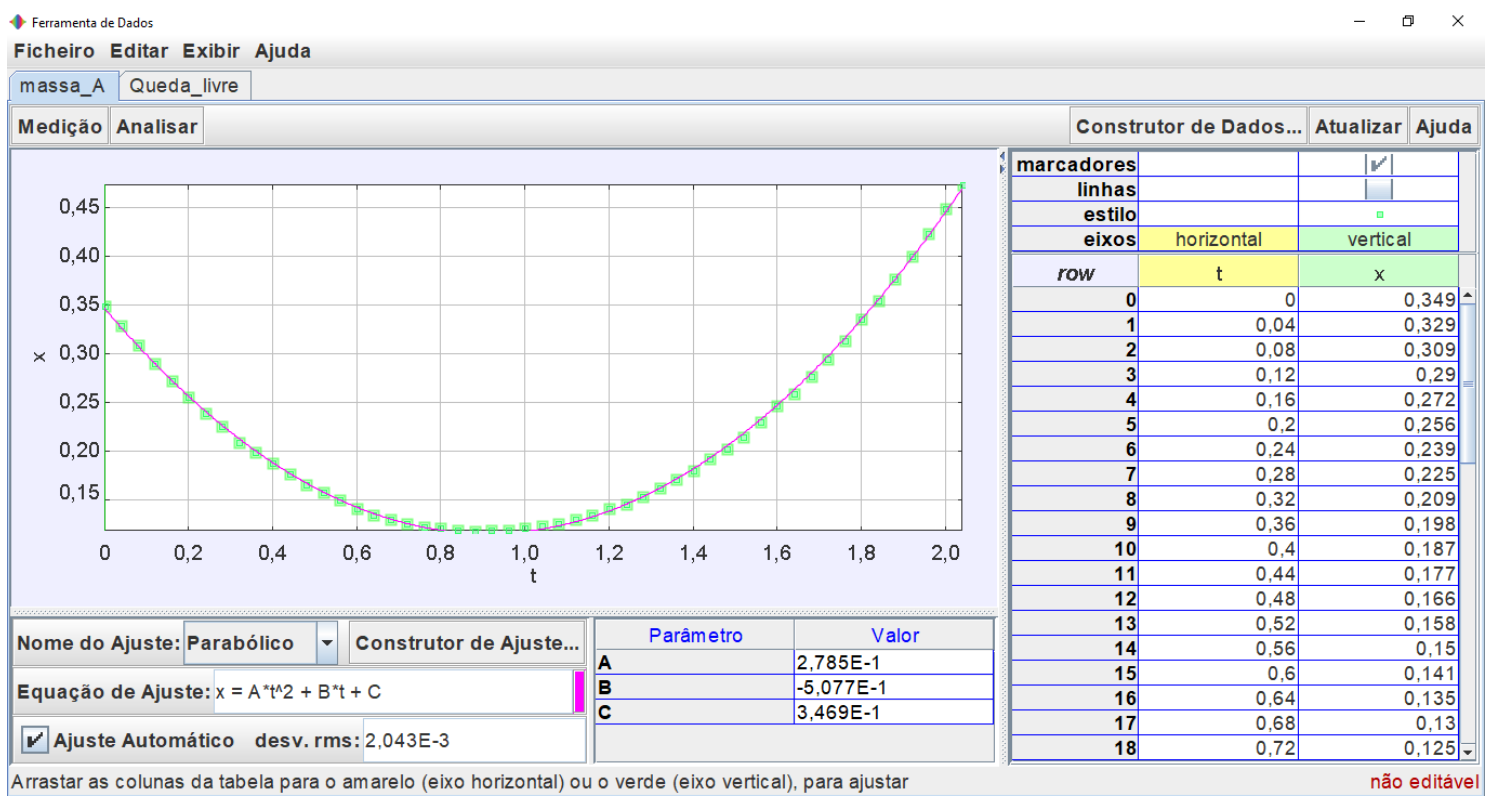

Fig. 4 - Gráfico x(t) do movimento do Flat Ball sobre o plano inclinado.

Para se fazer uma análise do movimento de queda livre, pode-se filmar um objeto que é jogado para o alto. Se as medidas são feitas cuidadosamente, dando-se atenção especial ao referencial de tamanho, um resultado bem próximo de $g=9,8 \mathrm{~m} / \mathrm{s}^{2}$ será obtido. Pode-se propor aos alunos que objetos de diferentes pesos sejam lançados, possibilitando a conclusão de que a aceleração da gravidade não depende do peso do objeto.

A Fig. 5 apresenta a tela do Tracker em que foram coletados os dados de um movimento de queda livre e a Fig. 6 mostra o gráfico experimental juntamente ao ajuste de uma função parabólica. A linha rosa representa a função de $2^{\circ}$ grau e os pontos verdes simbolizam os dados experimentais. Observa-se, visualmente, que a função parabólica se ajusta bem aos pontos experimentais. A função gerada pelo Tracker foi $y=5,1 t^{2}-3,6 t+1,3$. O dqm = 0,005 , que é um valor bem pequeno se comparado aos valores de distâncias percorridas pelo objeto, também indica que o ajuste foi adequado. O coeficiente quadrático é igual à aceleração do objeto dividida por dois, de forma que se conclui que a aceleração foi $10,2 \mathrm{~m} / \mathrm{s}^{2}$, valor próximo do esperado, $g=9,8 \mathrm{~m} / \mathrm{s}^{2}$.

\section{III.3.2 Avaliando efeitos da resistência do ar}

Diferentes objetos caindo podem sofrer mais ou menos o efeito da resistência do ar. Pode-se perguntar até que ponto determinado movimento de queda é adequadamente modelado como queda livre. A resposta a essa questão pode ser obtida observando-se um bom ou um 
mal ajuste de uma parábola aos dados experimentais da posição em função do tempo, com aceleração correspondente próxima a 9,8 $\mathrm{m} / \mathrm{s}^{2}$.

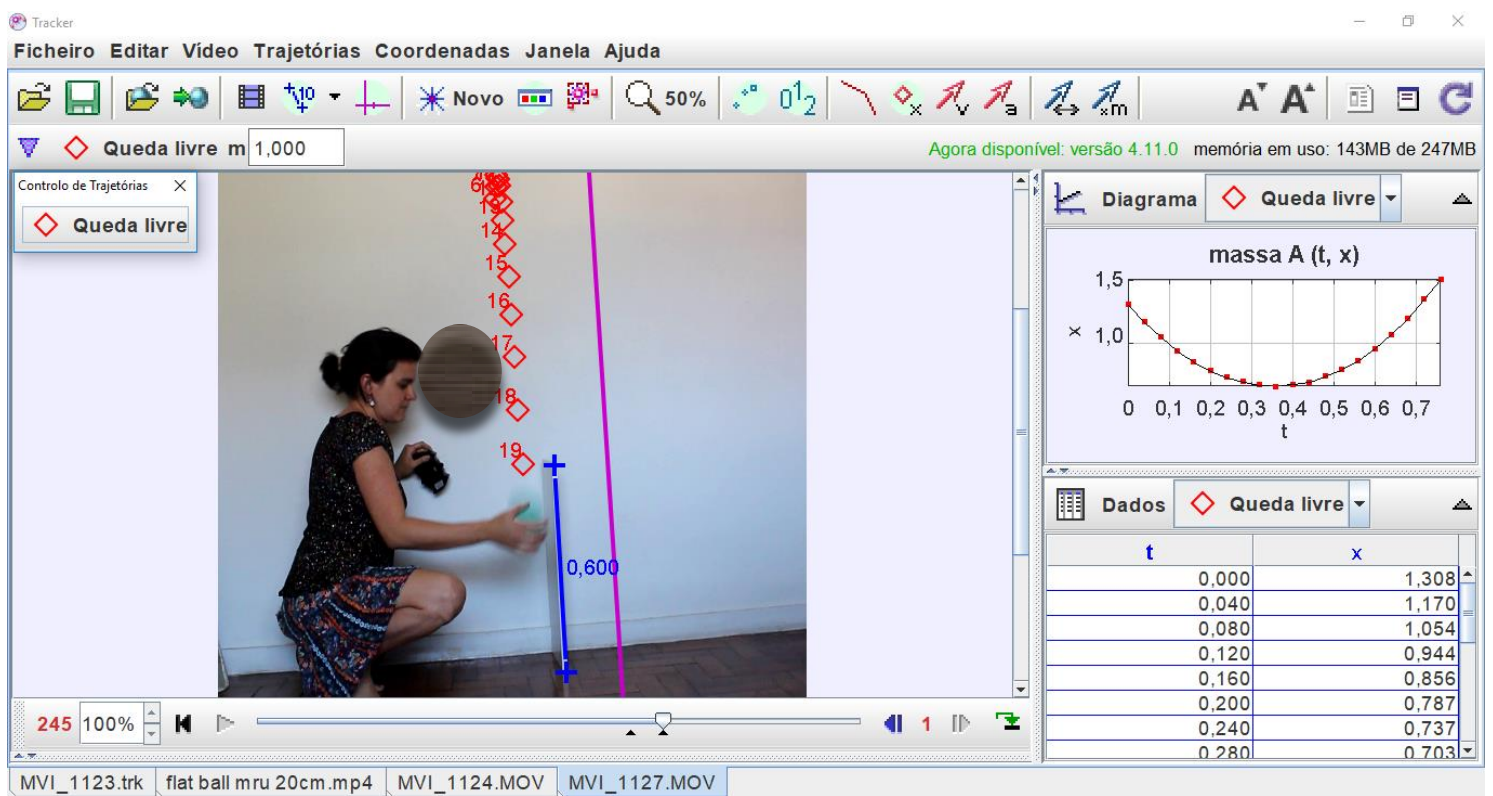

Fig. 5 - Tela de aquisição de dados do movimento de queda livre.

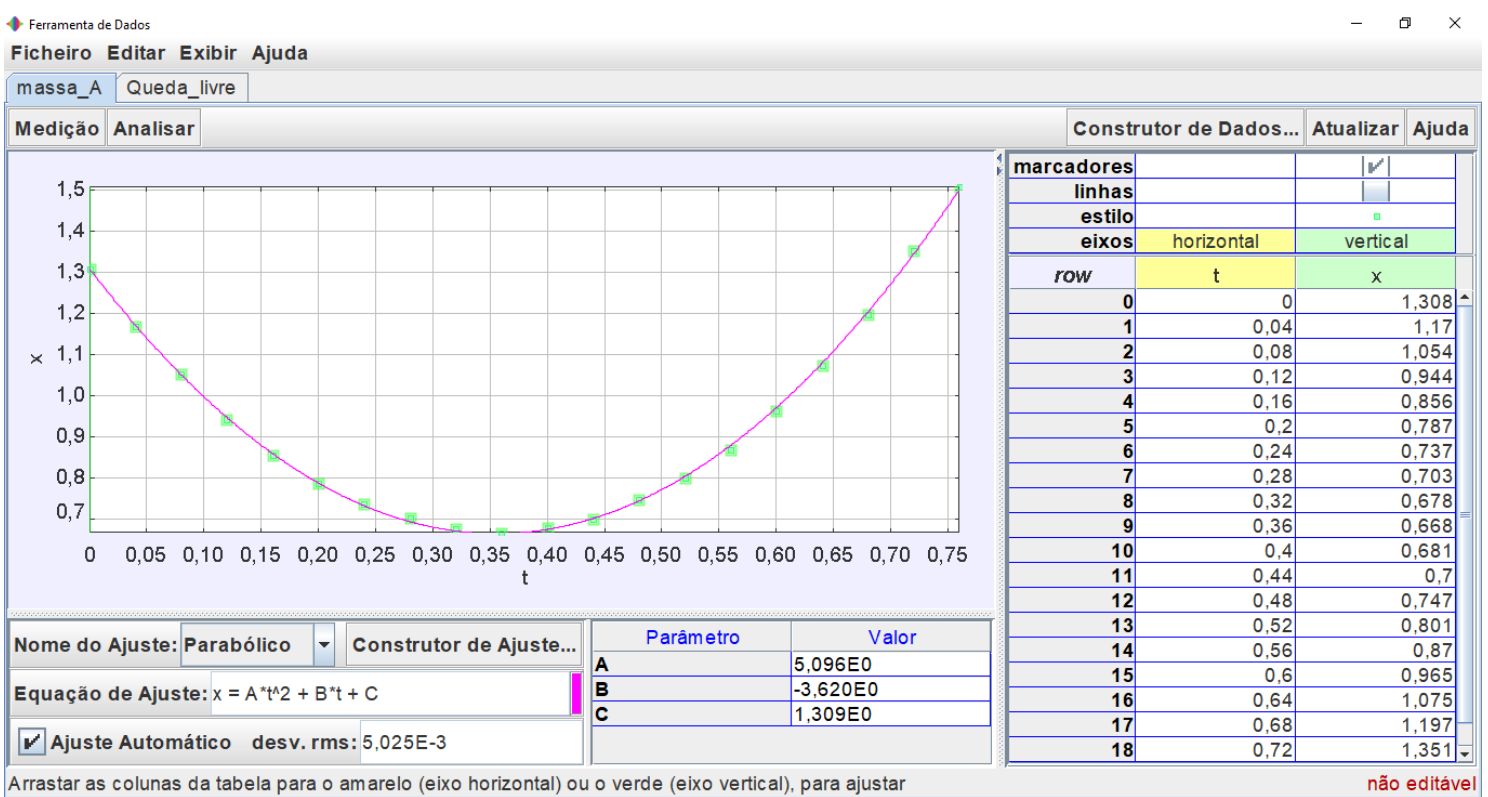

Fig. 6-Gráfico x(t) do movimento de queda livre.

A Fig. 7 apresenta a tela de aquisição das medidas e a Fig. 8 traz os gráficos de $x(t)$ para a queda de dois objetos, um bloco de madeira e um copo de plástico. Observa-se que os espaçamentos entre as posições do bloco de madeira vão ficando progressivamente maiores do que os do copo de plástico, indicando que o bloco de madeira adquire, cada vez mais, velocidades maiores que o copo de plástico. 
Aos dois conjuntos de dados experimentais foram ajustadas funções do $2^{\circ}$ grau. A função encontrada para a queda do bloco de madeira foi $x(t)=5,0 t^{2}-2,6 t+0,34$ e para o copo de plástico $x(t)=2,2 t^{2}-7,8 t+6,9$. Visualmente, a parábola referente ao movimento do bloco de madeira é melhor ajustada que a do copo de plástico. Mas os indícios mais fortes de que o movimento do bloco de madeira pode ser considerado como queda livre e o do copo de plástico não pode estão nos valores dos coeficientes quadráticos e dos dqms de cada um dos movimentos. Os coeficientes dos termos quadráticos são: 5,0 para o bloco de madeira, o que implica em uma aceleração de $10 \mathrm{~m} / \mathrm{s}^{2}$; e 2,2 para o copo de plástico, que corresponderia, se fosse esse um movimento com aceleração constante, a uma aceleração de $4,4 \mathrm{~m} / \mathrm{s}^{2}$, valor muito diferente dos $9,8 \mathrm{~m} / \mathrm{s}^{2}$ referente à aceleração da gravidade conhecida. Os dqms, 0,004 (bloco) e 0,01 (copo), mostram que os valores experimentais da posição em função do tempo se ajustam melhor a uma parábola no caso do movimento do bloco do que no do copo. Portanto, a resistência do ar não exerce influência considerável no movimento do bloco, sendo praticamente desprezível.
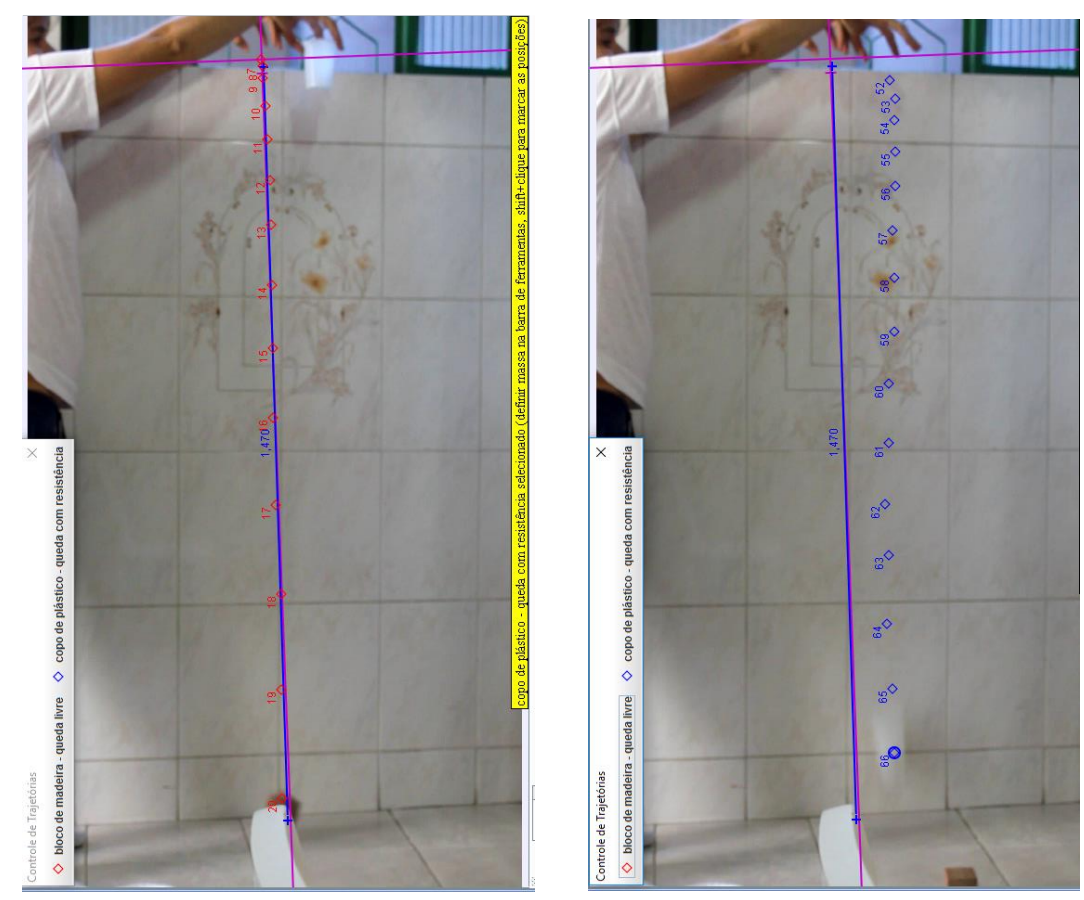

Fig. 7 - Queda livre de um bloco de madeira e queda com resistência do ar de um copo de plástico.

Analisando ainda os efeitos da resistência do ar, a perda de energia mecânica na queda de diversos objetos pode ser calculada. Também é interessante observar o mesmo objeto caindo de diferentes alturas, objetos de mesmo tamanho e pesos diferentes, e ainda objetos de mesmo peso e formas diferentes, a fim de se avaliar em quais dos movimentos a resistência do ar exerce muita influência e em quais deles tal resistência é desprezível. 


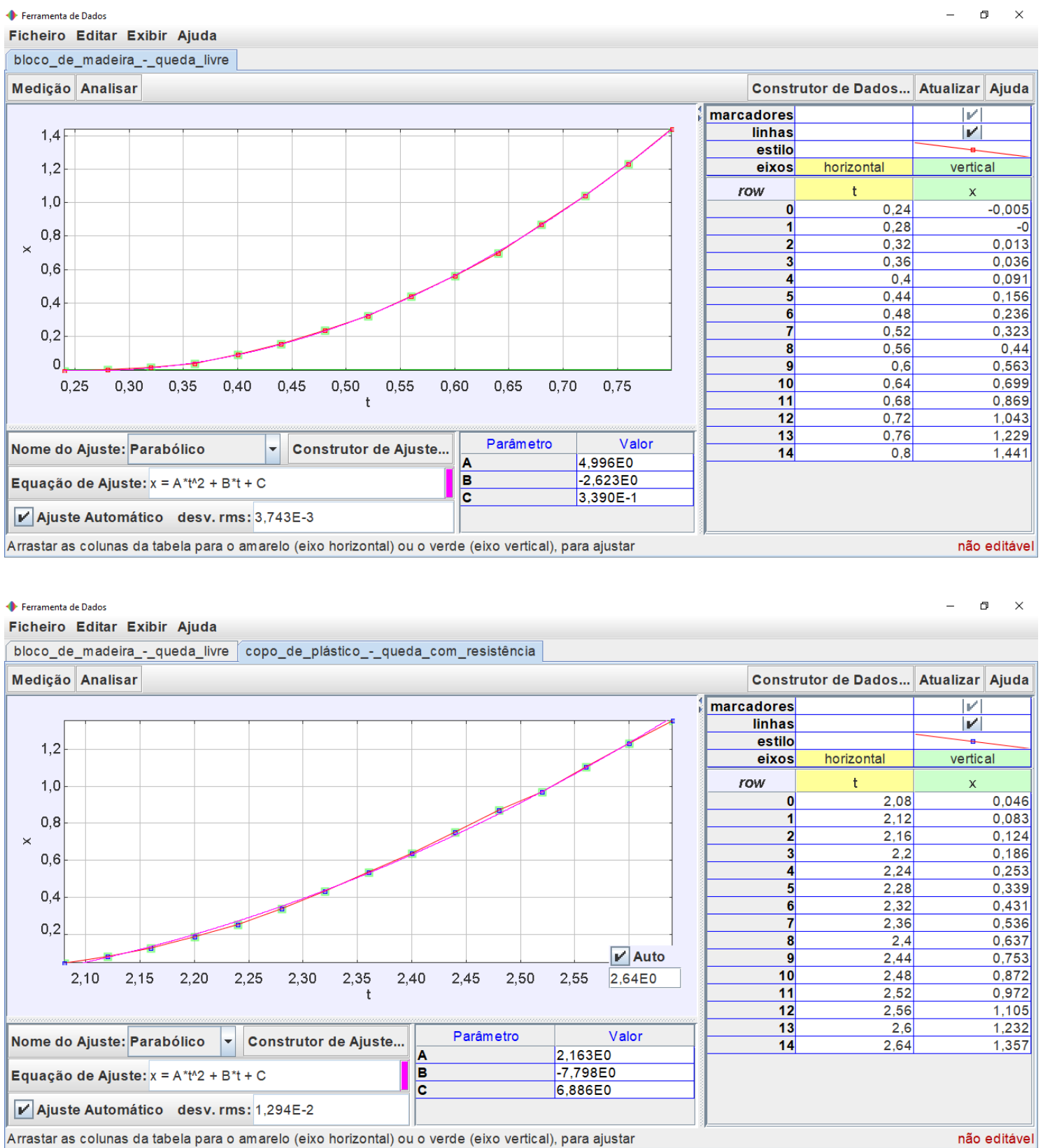

Fig. 8 - Gráficos dos dados experimentais e das funções de $2^{\circ}$ grau ajustadas às posições em função do tempo para o bloco de madeira e para o copo de plástico em queda.

Se o objeto é solto a partir do repouso e cai até um nível de energia potencial gravitacional nula, a energia inicial será potencial gravitacional e a final será cinética. A perda percentual de energia mecânica pode então ser calculada como $\Delta E_{m e c}(\%)=\frac{E_{m e c, f-E_{m e c, i}}}{E_{m e c, i}} \times$ $100=\frac{E_{c, f-E_{p g, i}}}{E_{p g, i}} \times 100=\left(\frac{m v^{2} / 2}{m g h}-1\right) \times 100=\left(\frac{v^{2}}{2 g h}-1\right) \times 100$. A velocidade final e a altura da queda podem ser lidas no Tracker. Dessa forma pode-se avaliar, em diversas situações, qual é a real influência da resistência do ar em um movimento, bem como discutir com 
os estudantes quão válida é a assertiva “despreze os efeitos da resistência do ar”, sempre muito presente nos textos didáticos de física.

No experimento do copo caindo, a altura da queda e a velocidade final foram, respectivamente, $1,23 \mathrm{~m}$ e $3,2 \mathrm{~m} / \mathrm{s}$, correspondendo a uma perda de energia mecânica de $-58 \%$. Para o bloco de madeira, $h=1,23 \mathrm{~m}$ e $v_{f}=4,9 \mathrm{~m} / \mathrm{s}$, resultando em uma variação de energia mecânica de $-0,4 \%$, valor muito próximo de zero, como esperado.

\section{III.4 Movimento de projétil - verificando independência das componentes horizontal e vertical}

A videoanálisecom o Tracker é muito apropriada para se verificar que, para o movimento de um projétil, a componente horizontal da posição em função do tempo pode ser representada por uma função de $1^{\circ}$ grau, ou seja, tem velocidade constante, e a componente vertical pode ser representada por uma função de $2^{\circ}$ grau cujo coeficiente quadrático fica próximo de $\frac{9,8 \mathrm{~m} / \mathrm{s}^{2}}{2}$, ou seja, é do tipo queda livre. Essa análise é muito semelhante ao que já foi descrito anteriormente nos tópicos referentes ao MRU e ao MRUV e não será repetida aqui.

Um outro aspecto interessante de ser verificado neste caso é o formato parabólico da trajetória. É possível fazer o gráfico $y(x)$ e ajustar uma parábola. A Fig. 9 mostra a tela do Tracker em que foram feitas medidas da posição em função do tempo de um objeto com movimento de projétil e a Fig. 10 traz o gráfico $y(x)$ dessa trajetória, com ajuste de função de $2^{\circ}$ grau. Vê-se que a parábola se ajustou bem aos dados experimentais, correspondendo a um $d q m=0,004$.

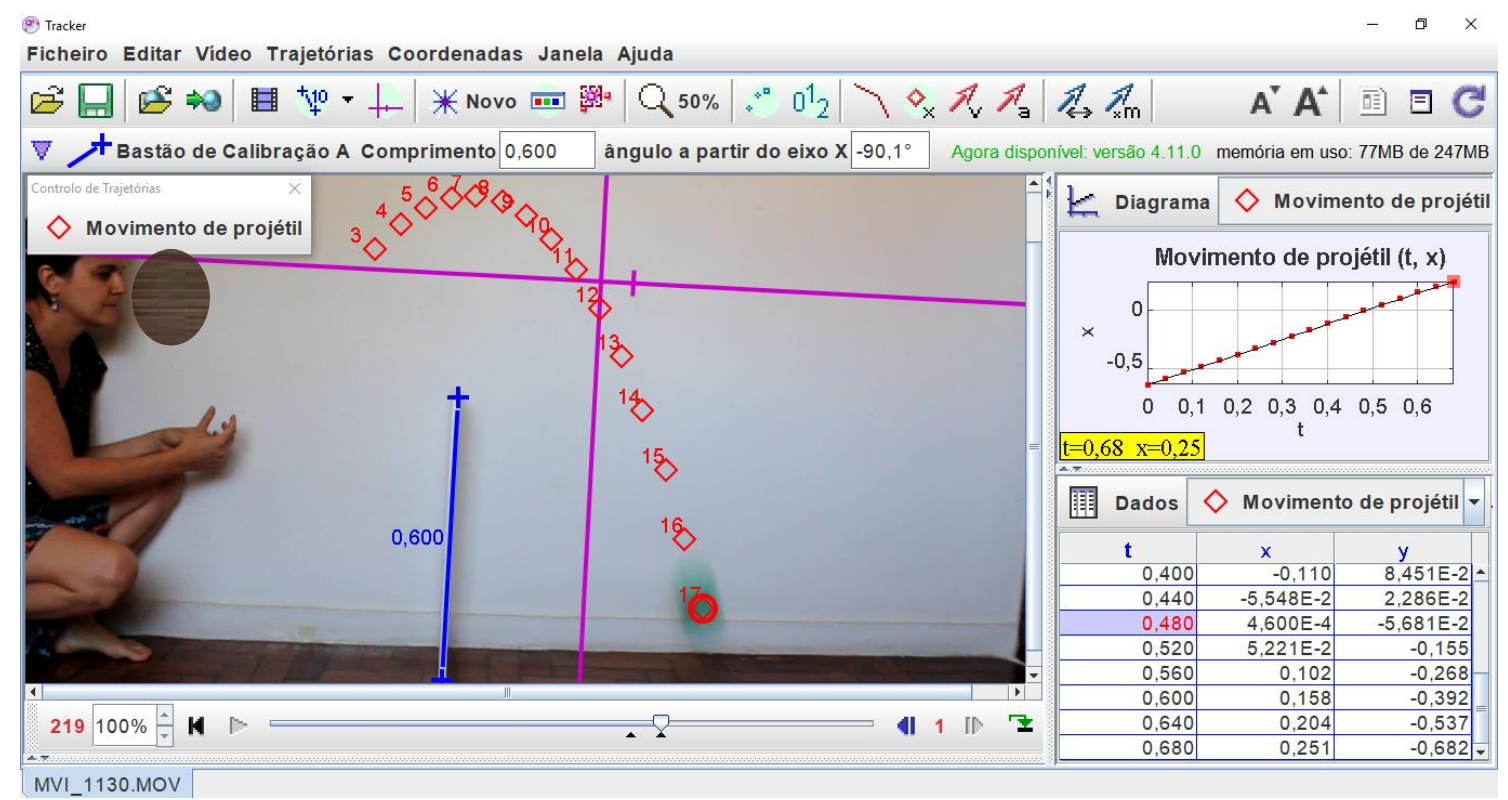

Fig. 9 - Tela da aquisição de dados $x(t)$ para o movimento de projétil. 


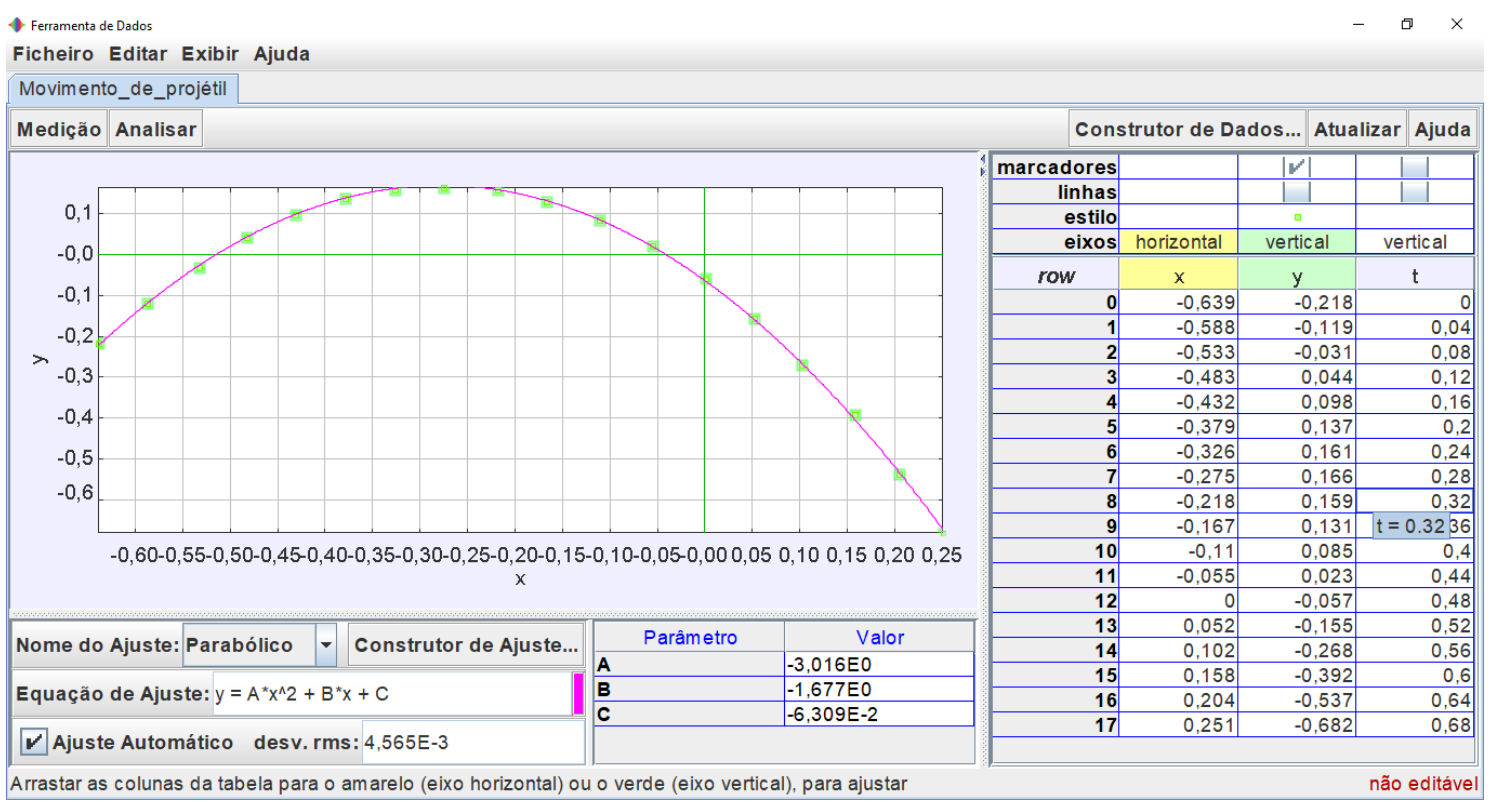

Fig. 10 - Gráfico y(x) de um movimento de projétil.

\section{III.5 Máquina de Atwood}

A máquina de Atwood consiste em uma corda que passa por uma polia com um objeto atado a cada uma de suas extremidades, como ilustrado na fotografia da Fig. 11. Sendo os pesos de cada um dos objetos conhecidos, é possível prever, através da $2^{\mathrm{a}}$ lei de Newton, qual será a aceleração do conjunto quando nenhuma outra influência, além de seus pesos e da força da polia sobre a corda, atua sobre a máquina. O resultado obtido é: $a=\frac{g\left(m_{p}-m_{l}\right)}{m_{p}+m_{l}}$, sendo $g$ a aceleração da gravidade, $m_{p}$ a massa do objeto mais pesado e $m_{l}$ a massa do objeto mais leve.

Para que essa experiência seja feita em sala, deve-se ter à disposição uma polia, um fio e uma balança, para pesar os objetos. A aceleração do movimento pode ser medida pelo Tracker. Trata-se de um MRUV. Poderemos, então, confrontar a aceleração calculada teoricamente com o resultado experimentalmente obtido. É uma forma de se verificar a validade da $2^{\mathrm{a}}$ lei de Newton na previsão das características do movimento dos objetos.

O valor da tensão no fio durante o movimento também pode ser previsto através da $2^{\text {a }}$ lei de Newton, a partir do conhecimento das massas dos objetos, o resultado obtido é: $T=\frac{2 g m_{p} m_{l}}{m_{p}+m_{l}}$. Se acoplarmos um dinamômetro a um dos objetos, poderemos obter a tensão do fio. Essa medida não é muito fácil de ser feita, pois o dinamômetro estará em movimento, mas é possível verificar um resultado próximo ao obtido teoricamente. Nesse caso, para o cálculo da tensão, a massa do dinamômetro deve ser somada à massa do objeto ao qual ele foi conectado. A extremidade móvel do dinamômetro deve ficar atada à corda e não ao objeto.

Em uma execução prática do experimento ora relatado, foram utilizados objetos de massas correspondentes a $218 \mathrm{~g}$ e $260 \mathrm{~g}$. Pela aplicação teórica da $2^{\mathrm{a}}$ lei de Newton, a aceleração do sistema em movimento seria de $0,86 \mathrm{~m} / \mathrm{s}^{2}$, e a aceleração obtida pela da análise 
com o Tracker foi de $0,76 \mathrm{~m} / \mathrm{s}^{2}$, valores razoavelmente próximos. Como já foi explicitado, a tensão durante o movimento é uma medida difícil de se obter; contudo, a leitura do dinamômetro revela claramente um valor intermediário entre os pesos de $2,1 \mathrm{~N}$ e 2,5N, confirmando também o valor previsto pela $2^{\mathrm{a}}$ lei: $2,3 \mathrm{~N}$.

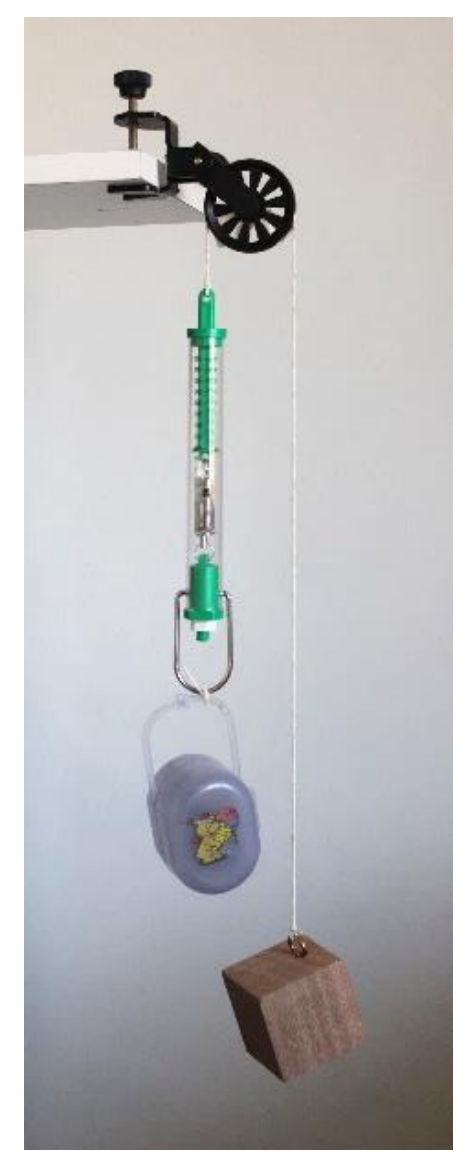

Fig. 11 - Fotografia da máquina de Atwood.

\section{III.6 Movimento harmônico simples - Massa-mola vertical}

O movimento harmônico simples de um sistema massa-mola pode ser bem explorado através de uma videoanálise. Prendendo-se um objeto à extremidade de uma mola e deixandoo oscilar verticalmente, é possível filmar algumas oscilações e utilizar o Tracker para obter os valores de posição em função do tempo para o trajeto durante tais oscilações.

A análise dos dados permitirá a visualização gráfica da conservação da energia mecânica. A partir dos valores $x(t)$ medidos, o programa calcula as velocidades em cada instante. Pode-se definir, no próprio Tracker, fórmulas para o cálculo das energias cinética, potencial gravitacional, potencial elástica e mecânica. Para que os valores referentes a essas grandezas sejam calculados em cada instante, é necessário fornecer, além da posição e da velocidade, a massa do objeto pendente, a constante elástica da mola e a aceleração da gravidade. 
A constante elástica da mola pode ser medida pela lei de Hooke, $F_{\text {mola }}=k x$, pendurando-se um objeto de peso conhecido e medindo a deformação da mola, $x$, ou através da relação $T=2 \pi \sqrt{\frac{m}{k}}$, medindo-se os valores do período, $T$, e da massa, $m$.

Os gráficos das diferentes energias envolvidas no movimento em função do tempo podem ser representados em um único plano cartesiano. A fotografia de uma montagem experimental da situação em análise está na Fig. 12

Fig. 12 e o gráfico das energias em função do tempo na Fig. 13. Utilizou-se um objeto de massa $226 \mathrm{~g}$ e uma mola de constante elástica 6,3 $\mathrm{N} / \mathrm{m}$. Observa-se, no gráfico, a oscilação periódica da energia cinética e das energias potenciais e a estabilização temporal da energia mecânica, como era de se esperar pelo princípio de conservação da energia mecânica.

Ao fazer o experimento, deve-se ter o cuidado de utilizar um objeto de massa muito maior que a massa da mola, de forma que este último valor seja desprezível, e também de centralizar-se o sistema de referência no ponto onde a mola esteja na vertical e relaxada, ainda sem o objeto pendurado.

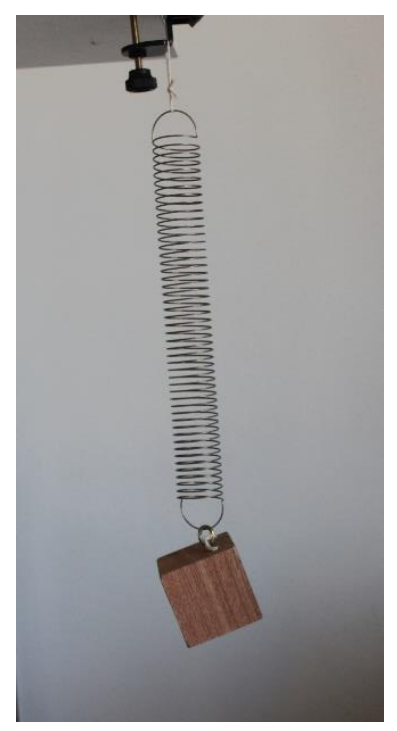

Fig. 12 - Fotografia do sistema massa mola vertical.

\section{III.7 Medida do coeficiente de atrito cinético entre um bloco e uma tábua}

\section{III.7.1 Medida 1 - Máquina de Atwood modificada}

Um bloco deslizando sobre uma superfície sofre a ação da força de atrito e seu movimento é influenciado por ela. A observação das características desse trajeto pode conduzir ao cálculo do coeficiente de atrito cinético entre as duas superfícies em contato. Com tal intuito, pode-se amarrar o bloco em questão a um barbante e, na outra extremidade, prender outro objeto de massa conhecida. Uma polia deve ser fixada na extremidade da superfície plana. $\mathrm{O}$ bloco ficará sobre a superfície, horizontalmente posicionada, e o outro objeto será dependura- 
do. O fio que os une deve passar pela polia. A Fig. 14 ilustra essa montagem. Os objetos devem ser soltos a partir do repouso e o movimento de um deles deve ser filmado. Utilizando o Tracker é possível verificar que se trata de um MRUV e calcular o valor da aceleração.

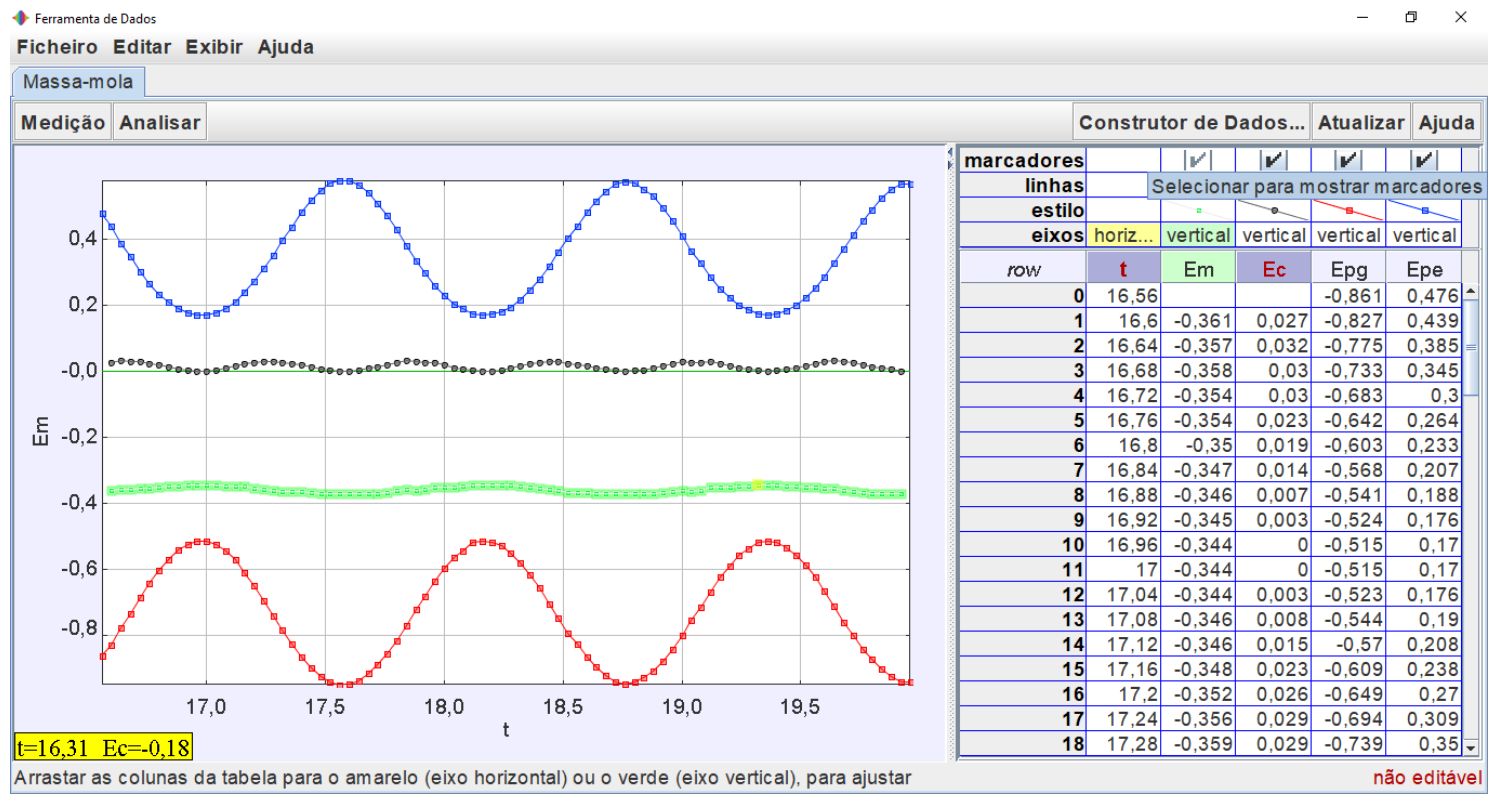

Fig. 13 - Gráficos das energias do sistema massa-mola vertical em função do tempo. Em verde está representada a energia mecânica, em azul a energia potencial elástica, em vermelho a energia potencial gravitacional e em preto a energia cinética.

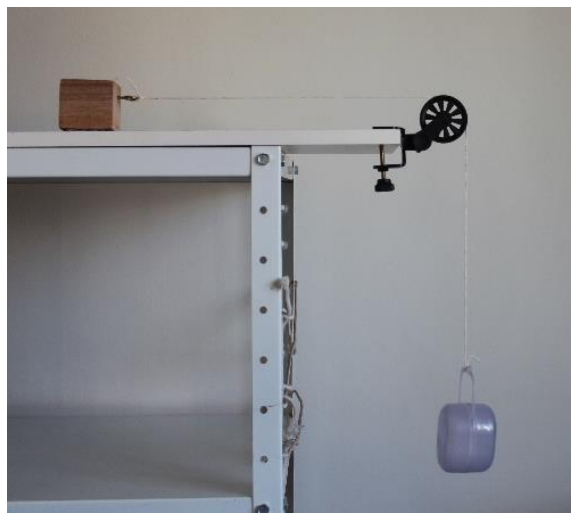

Fig. 14 - Máquina de Atwood modificada.

Essa montagem é chamada Máquina de Atwood modificada. A força resultante sobre os blocos em conjunto é a diferença entre o peso do objeto dependurado $\left(P_{d}\right)$ e a força de atrito sobre o bloco na superfície $\left(F_{a}\right), F_{R}=P_{d}-F_{a}$. A força de atrito é igual à força normal multiplicada pelo coeficiente de atrito $\left(F_{a}=\mu . N\right)$ e a normal é igual ao peso do bloco $\left(N=P_{b}\right)$. Aplicando-se a $2^{\text {a }}$ Lei de Newton ao sistema, o coeficiente de atrito pode então ser 
expresso como: $\mu=\frac{m_{d} g-\left(m_{b}+m_{d}\right) a}{m_{b} g}$. A partir do valor da aceleração obtida através do Tracker e dos valores das massas, pode-se calcular o coeficiente de atrito cinético entre o bloco e a superfície horizontal.

Em um experimento executado com a montagem da Fig. 14, foi feito um ajuste parabólico aos dados experimentais $x(t)$. O coeficiente quadrático encontrado foi 0,22 , correspondendo a uma aceleração de $0,44 \mathrm{~m} / \mathrm{s}^{2}$. As massas utilizadas foram $m_{d}=46 \mathrm{~g}$ e $m_{b}=$ $92 \mathrm{~g}$. A partir desses dados, chegou-se a um coeficiente de atrito cinético igual a 0,43.

\section{III.7.2 Medida 2 - Plano inclinado}

Apresenta-se a seguir outra montagem experimental para a medida do coeficiente de atrito. Inclinando a superfície, que anteriormente foi posicionada horizontalmente, de forma que o bloco possa escorregar, filma-se o seu movimento e mede-se a sua aceleração pelo Tracker. Trata-se de um MRUV.

Este é um movimento sobre um plano inclinado com atrito. A força resultante sobre o bloco na descida é igual à diferença entre a componente de seu peso na direção da rampa ( $P_{x}=m g \sin \theta$, sendo $\theta$ o ângulo que a rampa faz com a horizontal) e a força de atrito cinético $\left(F_{a}=\mu N=\mu P_{y}=\mu m g \cos \theta\right)$. Utilizando a $2^{\mathrm{a}}$ lei de Newton, tem-se: $m a=$ $m g \sin \theta-\mu m g \cos \theta$. Assim, o coeficiente de atrito cinético pode ser calculado novamente: $\mu=\frac{g \sin \theta-a}{g \cos \theta}$.

A Fig. 15 ilustra o plano inclinado. Em um experimento em que foi utilizada uma inclinação de $22,6^{\circ}$ (medida feita com aplicativo gratuito Bubble Level, para smartphone), a aceleração encontrada através do ajuste parabólico ao gráfico, no Tracker, foi $0,41 \mathrm{~m} / \mathrm{s}^{2}$, correspondendo a um coeficiente de atrito cinético de 0,37.

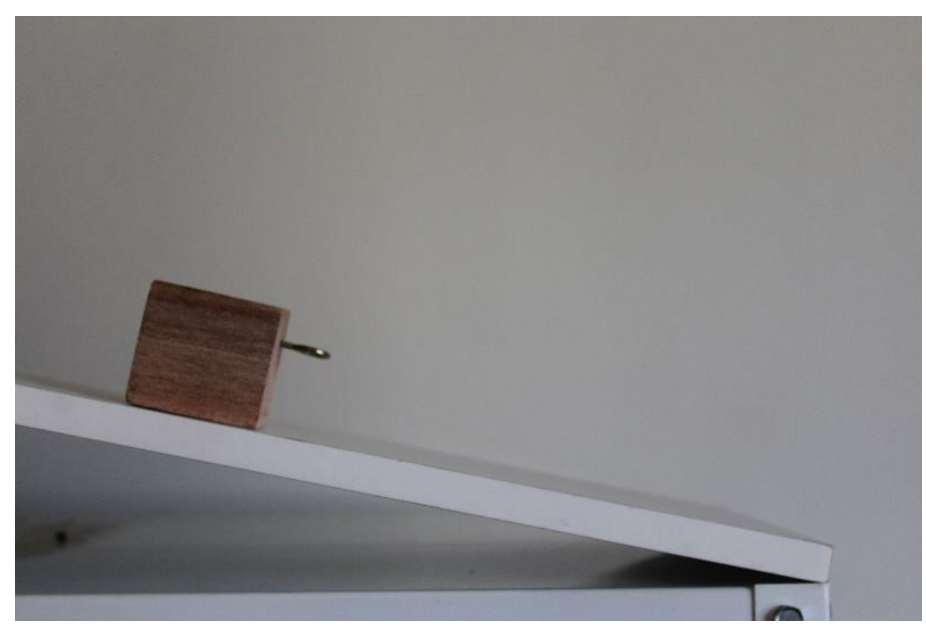

Fig. 15 - Bloco sobre um plano inclinado. 
Os resultados encontrados para o coeficiente de atrito, 0,43 e 0,37, diferem em 15\%. Essa diferença pode ter múltiplas origens: o fato de o plano não ser homogêneo, podendo haver regiões que geram maior ou menor atrito; imprecisões na determinação do referencial de tamanho no Tracker, ocasionando erros nas medidas de aceleração feitas a partir dele; imprecisões nas outras grandezas que compõem o cálculo de $\mu$ (as massas e a inclinação).

\section{III.7.3 Cálculo do coeficiente pelo teorema trabalho-energia}

Através de outra abordagem, o cálculo do coeficiente de atrito cinético pode ser refeito a partir dos dados já coletados nos dois experimentos descritos anteriormente, agora utilizando-se os conceitos de trabalho e energia, ao invés da $2^{\text {a }}$ lei de Newton.

Nos dois eventos há conversão de energia potencial gravitacional em energia cinética, com dissipação de parte da energia pela ação do atrito. A variação da energia mecânica é igual ao trabalho realizado pela força de atrito: $\Delta E_{m e c}=W_{a t}$. Iniciando-se a observação dos movimentos a partir do repouso e considerando-se o referencial de energia potencial gravitacional nulo no ponto final do movimento, a energia inicial será unicamente potencial gravitacional e a energia final cinética, o que pode ser enunciado por: $\Delta E_{m e c}=E_{c f}-E_{p g i}$.

A energia gravitacional inicial pode ser calculada medindo-se o desnível $h$ entre os pontos inicial e final do movimento (no caso da máquina de Atwood modificada esta variação de energia se refere apenas ao objeto que desce): $E_{p g i}=m g h$.

A energia cinética final pode ser calculada através do valor da velocidade final que o Tracker fornece: $E_{c f}=\frac{M v^{2}}{2}$ (quando se utiliza a máquina de Atwood modificada, essa massa é a soma das massas do bloco e do objeto pendurado).

O trabalho do atrito é negativo e apresenta módulo igual ao produto do deslocamento do objeto que sofre o atrito pelo valor da força de atrito. Esta, por sua vez, pode ser medida multiplicando-se o coeficiente de atrito pela força normal: $W_{a t}=-F_{a} \Delta x=-N \mu \Delta x$.

Assim:

$$
\begin{gathered}
\Delta E_{m e c}=W_{a t} \\
\frac{M v^{2}}{2}-m g h=-N \mu \Delta x \\
\mu=\frac{1}{N \Delta x}\left(m g h-\frac{M v^{2}}{2}\right)
\end{gathered}
$$

No caso do plano inclinado: $M=m, h=\Delta x \sin \theta$ e $N=m g \cos \theta$, resultando em $\mu=\tan \theta-\frac{v^{2}}{2 g \Delta x \cos \theta}$. Já no caso da máquina de Atwood modificada: $M=m_{b}+m_{d}$, $m=m_{d}, \quad N=m_{b} g, \quad \Delta x=h$, portanto $\mu=\frac{m_{d}}{m_{b}}-\frac{\left(m_{b}+m_{d}\right) v^{2}}{2 m_{b} g \Delta x}$. Em ambos os casos, pode-se calcular novamente o valor do coeficiente de atrito, agora a partir dos valores de velocidade, massas e deslocamento. 


\section{III.8 Colisões}

O estudo da conservação de momento linear pode ser feito observando-se a colisão frontal entre dois brinquedos Flat Ball ou entre dois planadores no trilho de ar. As velocidades de cada um dos objetos que colidem, antes e depois da colisão, podem ser medidas através do Tracker. A partir dos valores das velocidades e das massas, pode-se propor aos alunos que investiguem se há conservação de alguma grandeza, apesar da colisão.

São exemplos de questões a serem propostas: O vetor velocidade do conjunto se conserva? E o vetor momento linear? E a energia cinética do conjunto?

As variações percentuais de cada uma dessas quantidades podem ser calculadas de modo que se verifique que a variação percentual do momento linear é muito menor do que as outras duas.

Na Fig. 16 é mostrada a captura da tela das medidas de posição e tempo para uma colisão de dois Flat Balls, no Tracker. Ambos têm movimentos retilíneos uniformes antes e depois da colisão. Manteve-se um dos objetos fixo e arremessou-se o segundo na direção do primeiro. Foram feitas algumas tentativas até que o movimento após a colisão ocorresse na mesma direção do movimento antes da colisão, de forma a restringir-se a uma análise unidimensional. É necessário medir quatro valores de velocidades: duas vezes para cada um dos brinquedos, sendo uma antes e outra após a colisão. A partir desses valores e das massas de cada objeto, é possível analisar se houve conservação de velocidade, momento linear e energia cinética.

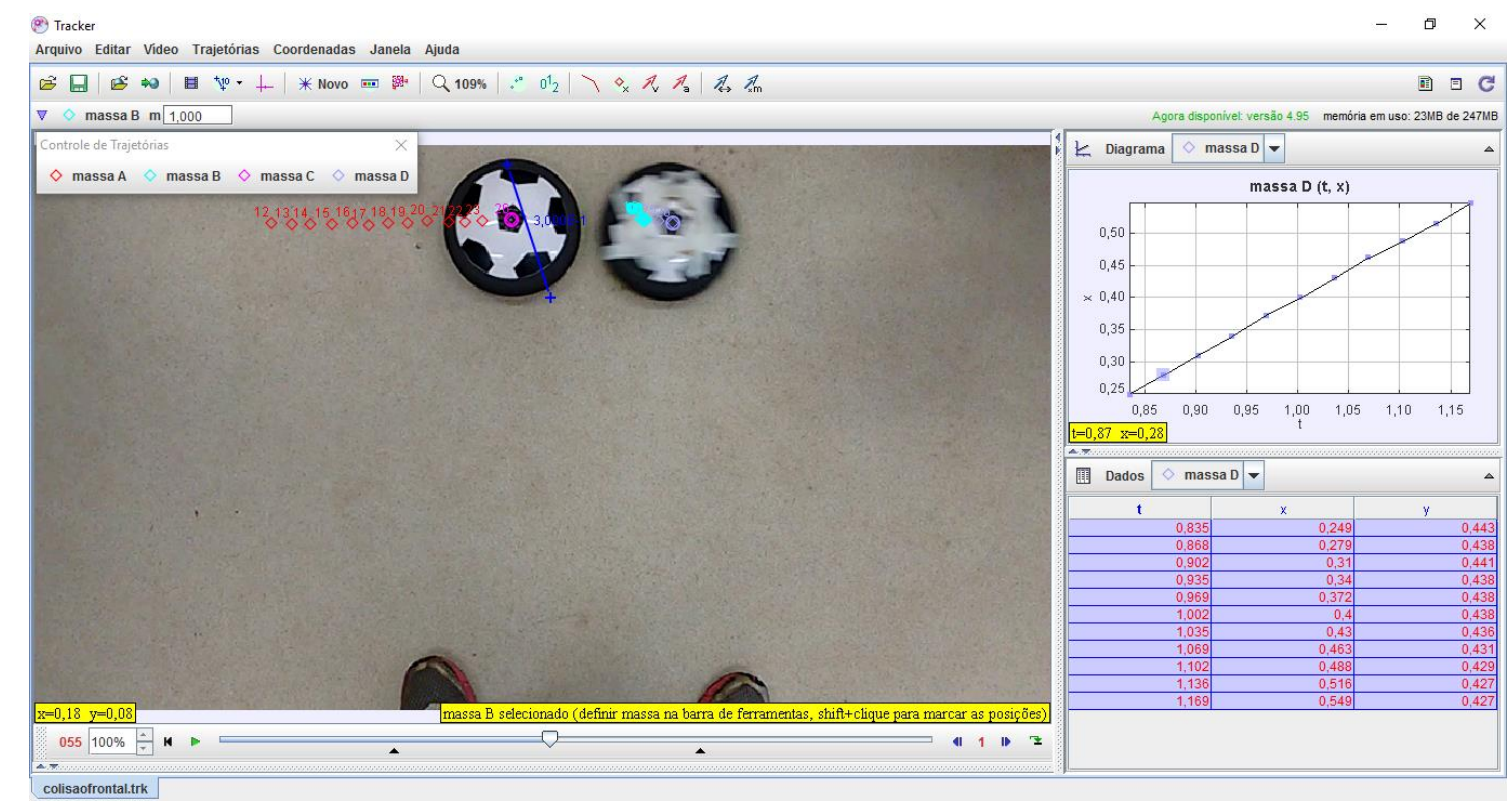

Fig. 16 - Captura da tela das medidas de posição em função do tempo para os Flat Balls, antes e depois da colisão. 
As massas dos Flat Balls foram $m_{1}=313 \mathrm{~g}$ e $m_{2}=376 \mathrm{~g}$. As velocidades encontradas foram: $v_{1 i}=1,25 \mathrm{~m} / \mathrm{s}, v_{2 i}=0 \mathrm{~m} / \mathrm{s}, v_{1 f}=0,11 \mathrm{~m} / \mathrm{s}, v_{2 f}=0,89 \mathrm{~m} / \mathrm{s}$. A seguir estão os resultados referentes às variações de velocidade, momento linear e energia cinética, antes e depois da colisão:

a) Velocidade

Variação percentual da velocidade: $\frac{\Delta v}{v_{\text {in }}} \times 100=20 \%$

A velocidade total não se conservou, ela diminuiu.

b) Energia cinética

Variação percentual da energia mecânica: $\frac{\Delta E_{m e c}}{E_{m e c, i n}} \times 100=38 \%$

Não houve conservação de energia mecânica. Ela diminuiu, tendo sido convertida em energia sonora e energia térmica.

c) Momento linear

Variação percentual do momento linear: $\frac{\Delta p}{p_{\text {in }}} \times 100=6 \%$

Os momentos lineares inicial e final tiveram valores próximos. A diferença entre um e outro se deve a limitações de precisão do processo de medição.

Também é possível analisar colisões em duas dimensões, avaliando a conservação de momento linear em cada uma das direções separadamente.

\section{III.9 Rotação - Medida do momento de inércia}

Quando um objeto circular, de simetria cilíndrica, rola descendo uma rampa, sem deslizar, sua aceleração e, consequentemente, a velocidade atingida e o tempo gasto para percorrer o trajeto dependem de seu momento de inércia. A aceleração, $a$, pode ser prevista pela

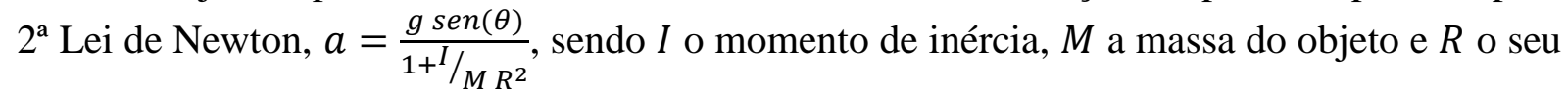
raio, em caso de a dissipação de energia ser desprezível.

A montagem desse experimento é feita com um objeto circular que possa ser deixado sobre uma rampa para descer rolando. Filma-se o movimento e calcula-se a sua aceleração a partir do Tracker. O movimento será MRUV. Uma vez obtidos os valores da aceleração, da massa e do raio, calcula-se o momento de inércia. Se o objeto apresentar uma expressão simples para o cálculo de seu momento de inércia, como um cilindro ou uma esfera, pode-se, ainda, fazer o cálculo do momento de inércia utilizando tal expressão e comparar o resultado obtido com o valor encontrado através da medida com o Tracker.

A seguir é apresentado o resultado de uma experiência dessa natureza. Utilizou-se um cilindro vazado, feito de aço. A Fig. 17 ilustra a captura da tela na qual se obtiveram os dados para o movimento da esfera. O cilindro desceu uma rampa inclinada a $3,1^{\circ}$. De raio interno $r_{i}=5,9 \mathrm{~mm}$, raio externo $r_{e}=13,5 \mathrm{~mm}$ e massa, $m=80 \mathrm{~g}$. A aceleração medida 
pelo Tracker foi $a=0,32 \mathrm{~m} / \mathrm{s}^{2}$, correspondendo a um momento de inércia experimental $I_{\text {exp }}=9,6 \times 10^{-6} \mathrm{~kg} \cdot \mathrm{m}^{2}$, calculado pela $2^{\mathrm{a}}$ Lei de Newton. O momento de inércia também pode ser calculado pela expressão $I=\frac{m}{2}\left(r_{i}{ }^{2}+r_{e}{ }^{2}\right)$, obtendo-se $I_{\text {teo }}=8,7 \times 10^{-6} \mathrm{~kg} \cdot \mathrm{m}^{2}$.

Comparando-se os resultados teórico e experimental para o momento de inércia do cilindro vazado, verifica-se que não houve uma correspondência exata entre os valores obtidos, tendo sido observada uma variação de $10 \%$. O cálculo do momento de inércia é feito a partir de muitas grandezas, cada uma com seu próprio erro experimental, o que contribui para uma incerteza considerável no resultado final. Assim, tem-se como previsível a diferença entre os resultados encontrados.

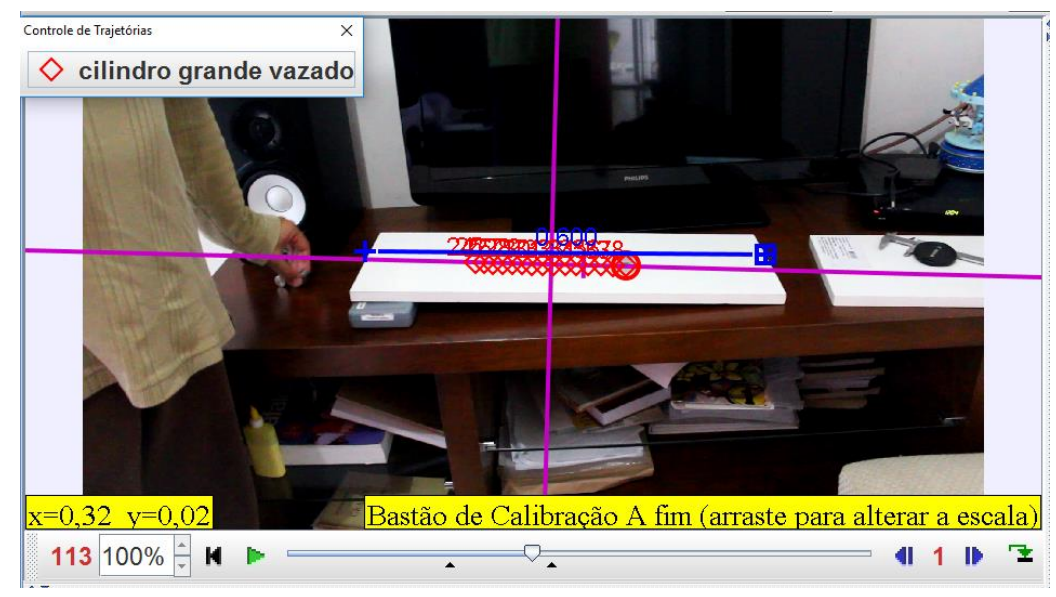

Fig. 17 - Obtenção dos dados do movimento da esfera rolando sobre um plano inclinado.

\section{Conclusões}

Neste trabalho apresentaram-se diversas atividades que podem ser abordadas experimentalmente em um curso de Mecânica, com o auxílio do programa de computador Tracker. Trata-se de situações-problema semelhantes àquelas usualmente estudadas em disciplinas que exploram esse assunto. Essa abordagem apresenta a grande vantagem de se substituir os eventos analisados em sala de aula, que tradicionalmente são representados através de desenhos, por montagens reais, utilizando-se valores reais para as grandezas envolvidas nos problemas. Os experimentos desenvolvidos, todos de baixo custo, contemplam integralmente os tópicos normalmente estudados em cursos de Mecânica no Ensino Médio e no ciclo básico do Ensino Superior.

Apresentamos apenas uma análise inicial acerca dos experimentos relatados neste texto. Assim, todos eles podem ser muito mais explorados, a partir do que foi exposto aqui. No estudo do movimento de um projétil, por exemplo, podem-se obter, no Tracker, os valores das componentes vertical e horizontal da velocidade, propondo-se aos estudantes o cálculo do alcance, da altura máxima e do tempo de voo. Todas essas grandezas, uma vez calculadas, podem ser comparadas com os valores lidos no próprio programa. 
O estudo do movimento com o auxílio do Tracker requer a utilização de diversas formas de representação do movimento dos experimentos, como diagramas de movimento, tabelas, gráficos e equações de movimento. A necessidade de coordenar e relacionar essas diferentes representações auxilia a concretização do conhecimento a respeito da Mecânica.

\section{Agradecimentos}

Agradeço a leitura generosa feita por Juana Esteves Parreira e Pablo Lima Saldanha, que contribuíram para a melhoria do texto.

\section{Referências}

BEZERRA, A. G. et al. Videoanálise com o software livre Tracker no laboratório didático de Física: movimento parabólico e segunda lei de Newton. Caderno Brasileiro de Ensino de Física, Florianópolis v. 29, n. Especial 1, p. 469-490, set. 2012.

BROWN, D. Tracker Video Analysis and Modeling Tool. Disponível em: <http://www.opensourcephysics.org/items/detail.cfm?ID=7365>. Acesso em: 20 jun. 2017.

BRYAN, J. Video analysis software and the investigation of the conservation of mechanical energy. Contemporary Issues in Technology and Teacher Education, Charlottesville, v. 4, n. 3, p. 284-298, 2004.

CHRISTIAN, W. et al. Open source physics. Science, Washington, v. 334, n. 6059, p. $1077-$ 1078, nov. 2011.

JESUS, V. L. B. Experimentos e Videoanálise - Dinâmica. São Paulo: Livraria da Física, 2014.

KLEIN, P. et al. Video analysis of projectile motion using tablet computers as experimental tools. Physics Education, Philadelphia, v. 49, n. 1, p. 37-40, jan. 2014.

LENZ, J. A. et al. Utilização de TIC para o estudo do movimento: alguns experimentos didáticos com o software Tracker. Abakós, Belo Horizonte, v. 2, n. 2, p. 24-34, maio 2014.

PARREIRA, J. E. Blog Professora Júlia Esteves Parreira, Sobre Ensino de Física. Disponível em: <http://www.icei.pucminas.br/professores/juliaparreira/50-2/>. Acesso em: 14 nov. 2018.

PHOMMARACH, S. et al. Video analisys of rolling cylinders. Physics Education, v. 47, n. 2, p. 189-196, mar. 2012. 
RODRIGUES, M.; CARVALHO, P. S. Teaching physics with Angry Birds: exploring the kinematics and dynamics of the game. Physics Education, Philadelphia, v. 48, n. 4, p. 431437, jul. 2013.

SIRISATHITKUL, C. et al. Digital video analysis of falling objects in air and liquid using Tracker. Revista Brasileira de Ensino de Física, São Paulo, v. 35, n. 1, fev. 2013.

WEE, L. K. et al. Using Tracker as a pedagogical tool for understanding projectile motion. Physics Education, Philadelphia, v. 47, n. 4, p. 448-455, jul. 2012.

WRASSE, A. C. et al. Investigando o impulso em crash tests utilizando videoanálise. Revista Brasileira de Ensino de Física, São Paulo, v. 36, n. 1, p. 1501-1 1050-6, fev. 2014. 